\title{
INTERACTION OF HYDROGEN WITH VANADIUM LAYERS PREADSORBED ON TUNGSTEN FIELD EMITTER TIP
}

\author{
R. Beaszczyszyn, E. Wachowicz and M. Blaszczyszynowa \\ Institute of Experimental Physics, University of Wrocław \\ Pl. Maxa Borna 9, 50-204 Wrocław, Poland
}

(Received January 14, 1998; in final form April 2, 1998)

\begin{abstract}
Interaction of hydrogen with vanadium layers preadsorbed on a thermally cleaned tungsten field emitter was studied at room temperature and $78 \mathrm{~K}$ through measurements of the total work function changes. An increase in the work function followed by its slight decrease at higher exposure can be understood taking into account the possibility of negatively $\left(\beta^{-}\right)$and positively $\left(\beta^{+}\right)$polarized adspecies formation on thin vanadium layer. This process leads to vanadium hydride formation. The work function results suggest that hydrogen diffusion into the vanadium layer is meaningful at room temperature. Thermal desorption of hydrogen adsorbate carried out within the temperature range $409-461 \mathrm{~K}$ from thin vanadium layer $\left(\Theta_{\mathrm{V}}=40\right)$ provided a value of $127 \pm 6 \mathrm{~kJ} / \mathrm{mol}$ for the activation energy for desorption.
\end{abstract}

PACS numbers: $79.70 .+q, 82.65 . \mathrm{My}$

\section{Introduction}

Interaction of hydrogen with metals has been widely investigated because of its great importance in a variety of fields in science and technology. Transition metals of VB group: vanadium, niobium, tantalum, and their alloys can dissolve large quantities of hydrogen in a small volume, forming hydrides [1-3]. For this reason hydrides can be applied to energy technology for storing the energy carrier hydrogen [1]. In contradistinction to surface, the bulk properties of vanadium hydride have been intensively studied [1-3]. The phase diagram shows [1] that the vanadium hydrides may consist of various phases: from the $\alpha$-disordered bcc solution, where $\mathrm{H}$ atoms are distributed randomly over tetrahedral $(\mathrm{T})$ sites, to ordered phases $\beta\left(\mathrm{V}_{2} / \mathrm{H}\right)$, etc., with $\mathrm{H}$ atoms occupying octahedral sites (O sites). The vanadium lattice in the $\beta$ phase is bct with the axial ratio $c / a=1.1[1,4]$. At a concentration corresponding to the formation of the dihydride phase $\gamma\left(\mathrm{V} / \mathrm{H}_{2}\right)$, the atomic structure bcc of the metal must transform to fcc to provide equivalent $\mathrm{T}$ sites [1]. The solubility of hydrogen in the $\alpha$ phase decreases with decreasing temperature [1]. From the X-ray diffuse-scattering experiments it has resulted that the diffusion process of $\mathrm{H}$ in $\mathrm{V}$ is dominated by quantum tunneling [5]. The 
studies of hydrogen in epitaxially grown $\mathrm{Mo} / \mathrm{V}$ single-crystal superlattice have shown that hydrogen is localized in $\mathrm{V}$ layers $[6,7]$. The solubility for hydrogen in the thin $V$ layers is higher than in the bulk vanadium [8]. In a paper [8] additional information has appeared on the thermodynamic properties of hydrogen in quasi-two-dimensional vanadium layers.

The results presented below concern the interaction of hydrogen with vanadium layers preadsorbed on a tungsten field emitter. Application of field emission (FE) technique allowed to observe the reaction on atomically modified substrate. The single-crystal apex of the FE emitter, which is covered with a layer of other metal, is a convenient model of a real metallic cluster which reveals simultaneously both close- and rough-packed faces [9]. The measurements were carried out for the entire emitter surface. However, from the work function variations and the analysis of FE images, the conclusions on the local microregions of vanadium layer active in the process of hydrides formation are drawn.

\section{Experimental procedure}

Experiments were carried out in the FE glass tube connected to a metal UHV system providing a base pressure of below $1.3 \times 10^{-8} \mathrm{~Pa}$. The tube was equipped with a vanadium source in the shape of a $V$ granule (Johnson-Matthey) spotwelded to two crossed tungsten loops. Vanadium doses were thermally equilibrated on the substrate at $1250-1310 \mathrm{~K}$ for $15-30 \mathrm{~s}$. The emitter temperature was controlled using a controller system and determined by resistance measurements of a loop segment with potential leads. The coverage of vanadium layers $\Theta_{\mathrm{V}}$ was determined from the dependence of the work function changes $\Delta \phi$ on adsorption time. Hydrogen (Messer Griesheim) could be admitted (after partial purification by immersing a small reservoir of $\mathrm{H}_{2}$ into liquid nitrogen coolant) via variable leak valve attached directly to the UHV system. A unipole mass spectrometer in the system made it possible to monitor residual gases and $\mathrm{H}_{2}$ purity; admitted gas proved to be free from detectable impurities. A purity of $\mathrm{H}_{2}$ was also tested by the thermal desorption experiment. According to [10] hydrogen is completely desorbed from the tungsten emitter at $600 \mathrm{~K}$. Analysis of FE images and Fowler-Nordheim $(\mathrm{F}-\mathrm{N})$ plots were made both before deposition of hydrogen and then after thermal desorption at $600 \mathrm{~K}$. The differences both in $\mathrm{FE}$ images and $\mathrm{F}-\mathrm{N}$ plots were not observed. The pressure of hydrogen was determined by means of an ionization gauge (with a correction) working at a reduced temperature of the cathode (with the electron current of $40 \mu \mathrm{A}$ ) to reduce the dissociation of $\mathrm{H}$ molecules. The gauge was placed apart from the FE tube. During exposure the valve between UHV pumps and channel with FE tube and the gauge was almost closed to reduce the pumping of hydrogen. After each exposüre to hydrogen (within the pressure range $10^{-7} \div 10^{-10} \mathrm{~Pa}$ ) hydrogen was pumped off and $\mathrm{F}-\mathrm{N}$ characteristics were taken at a pressure of $1.3 \div 2.6 \times 10^{-8} \mathrm{~Pa}$. Work function measurements were performed for the emitter kept at $78 \mathrm{~K}$ and room temperature.

The FE images were recorded by CCD video camera and the video signal was transferred to a video recorder and a computer. By using a special computer program the analyses of $\mathrm{FE}$ images were performed. This procedure allows also to estimate the work function for selected areas of the emitter surface by taking 
the modified $\mathrm{F}-\mathrm{N}$ characteristics: image intensity versus high voltage (the dependence of the intensities of the luminophore on the emission current was taken into consideration).

\section{Results and discussion}

\section{3:1. Work function dependences}

Work function results presented in this section were determined from the current-voltage $\mathrm{F}-\mathrm{N}$ characteristics. Figure 1 presents the dependence of the average work function $\phi$ of tungsten on vanadium coverage. It is assumed that a coverage close to $\Theta_{\mathrm{V}}=1$ corresponds to a weak minimum of $\phi$ in Fig. 1. Work

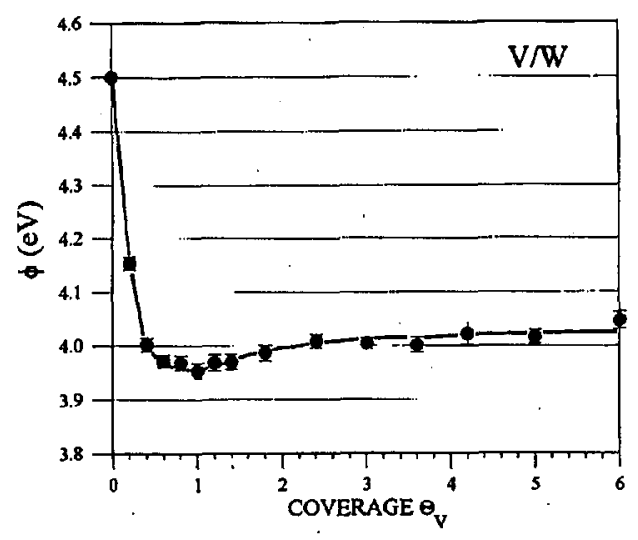

Fig. 1. Plot of the work function $\phi$ versus vanadium coverage on tungsten.

function measurements for hydrogen adsorption were carried out for the vanadium coverages: $0,1,2,3,4,6,10,12$, and 22 monolayers at $78 \mathrm{~K}$ and at room temperature except the measurements at $\Theta_{\mathrm{V}}=0$ and 10 which were performed only at room temperature. Examples of the results for vanadium coverage: 0, 1, 3, 4, 12, and 22 are presented in Figs. 2-7, respectively. The adsorption of hydrogen on tungsten at $78 \mathrm{~K}$ resulted in an additional increase in work function. In saturation of $\phi(\mathrm{H})$ this increase reached curve $0.06 \mathrm{eV}$. In general, our results for the hydrogen/tungsten system are in agreement with other papers [10-12].

Preadsorbed vanadium atoms change the character of work function dependence on hydrogen coverage. In general, with increasing vanadium coverage $\Theta_{\mathrm{V}}$, the increase in $\Delta \phi$ is reduced. In Figs. $4 \mathrm{~b}-7 \mathrm{~b}$ it is seen that at room temperature for $\Theta>3, \Delta \phi$ slightly decreases (after passing a small maximum) with increasing hydrogen coverage. For $78 \mathrm{~K}$ the dependences are more complicated. However, a small reduction of $\phi$ is also seen in Figs. 5a, 6a, 7a. It should be noted that changes of $\phi$ after exposition of vanadium layers to hydrogen are relatively small in relation to the error of the method. However, the main trend of the $\Delta \phi(\mathrm{H})$ behavior could be stated when large series of measurements were performed. 
The changes of $\Delta \phi$ can be understood taking into account the possibility of creation the negatively $\left(\beta^{-}\right)$and the positively $\left(\beta^{+}\right)$polarized adspecies on the vanadium layer leading to the formation of vanadium hydride. Such interpretation is suggested for explanation of the surface potential changes $\triangle S P$ measured during interaction of hydrogen with thin transition metal films which form hydrides, like

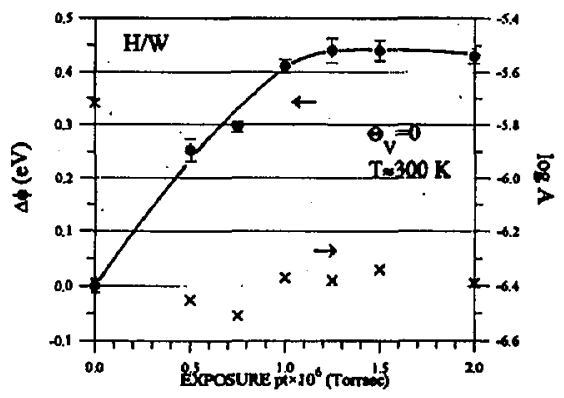

Fig. 2. Changes of the work function $\Delta \phi$ and logarithm of preexponential term $A$ of $\mathrm{F}-\mathrm{N}$ equation during adsorption of hydrogen on tungsten precovered with vanadium layers of $\Theta_{V}=0$ at $300 \mathrm{~K}$.
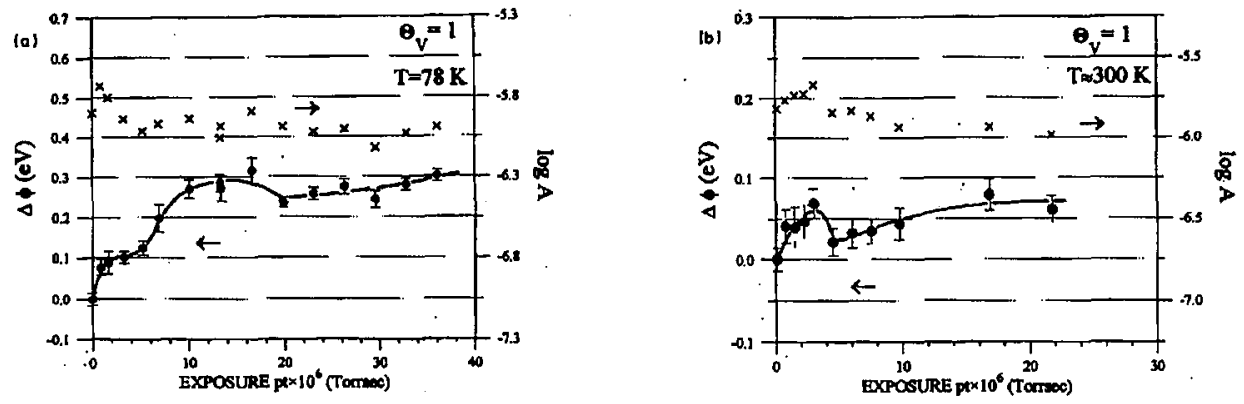

Figure 3.
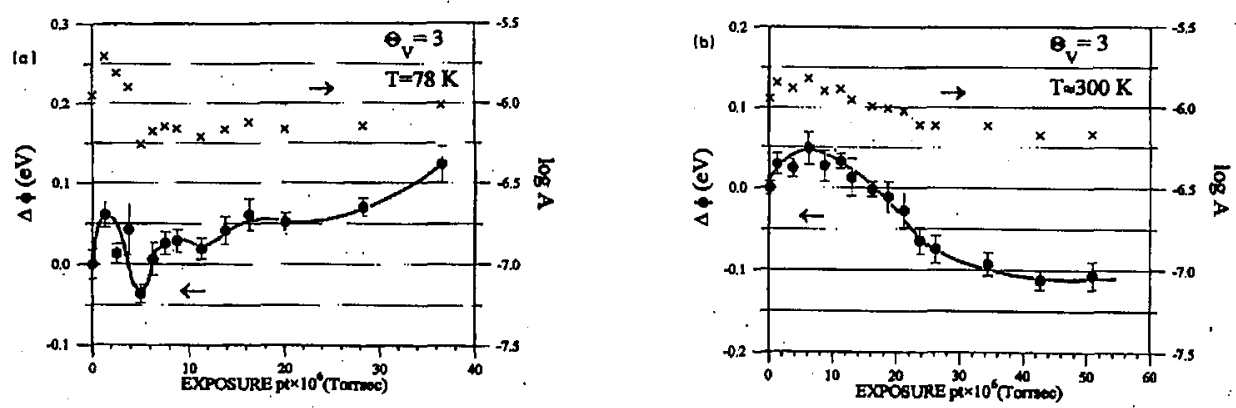

Figure 4. 
$\mathrm{Pd}[13,14], \mathrm{Nb}[15], \mathrm{Ni}[16], \mathrm{Ti}[17-19]$. The $\left(\beta^{-}\right)$and $\left(\beta^{+}\right)$adspecies can also be created in the case of transition metals that do not form hydrides, e.g. Pt [20]. Creation of $\beta^{-}$adspecies can be expected on the basis of Grimley's model [21].
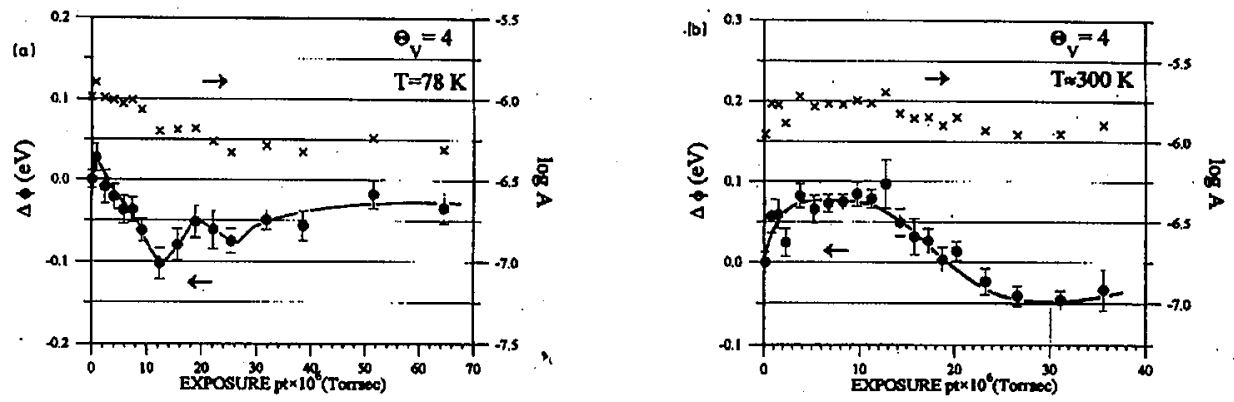

Figure 5.
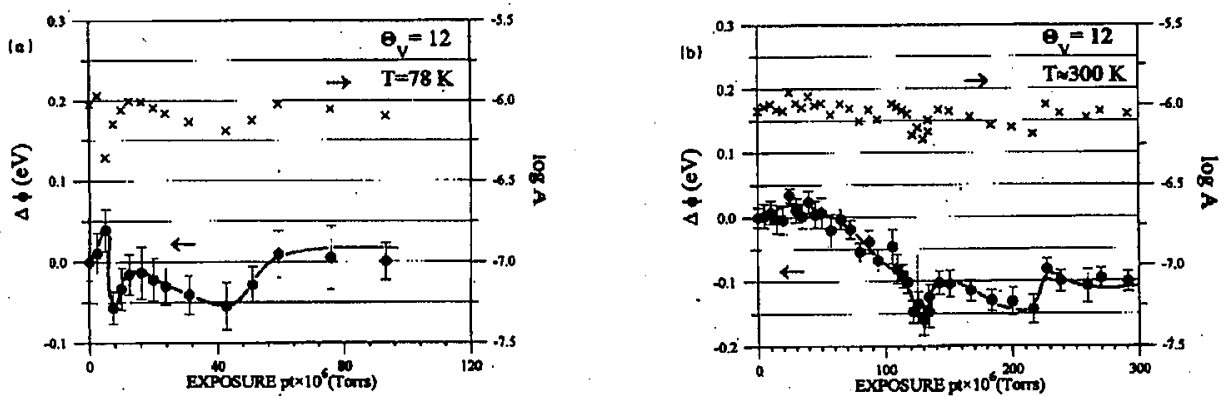

Figure 6.
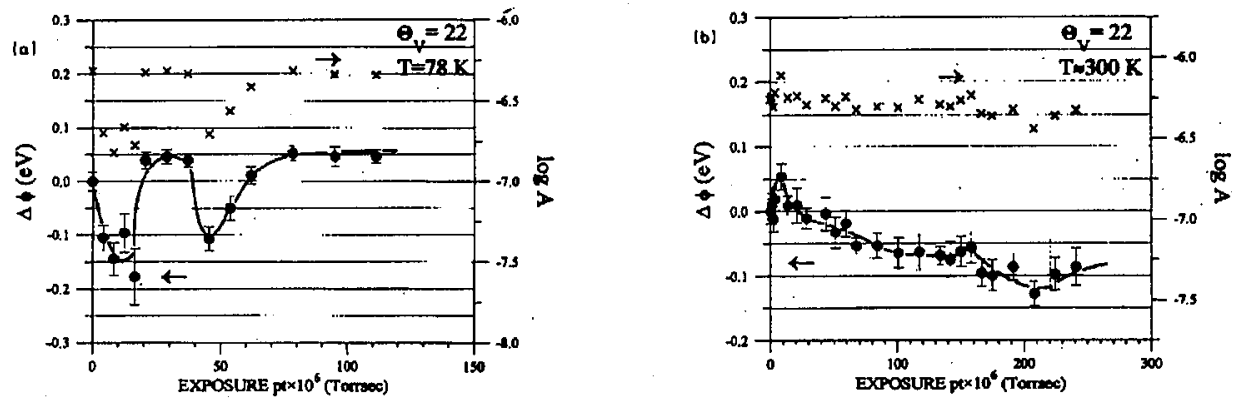

Figure 7.

Figures 3-7. Changes of the work function $\Delta \phi$ and logarithm of preexponential term $A$ of $\mathrm{F}-\mathrm{N}$ equation during adsorption of hydrogen on tungsten precovered with vanadium layers of $\Theta_{\mathrm{V}}=1,3,4,12,22$ (as indicated in the figures) at $78 \mathrm{~K}$ (a) and $300 \mathrm{~K}$ (b). Vertical dashed lines denote hydrogen exposure at the beginning of the saturation of $\Delta \phi$. 
Although the results presented in Figs. 1-7 concern the emission from the total emitter surface, the changes of $\Delta \phi$ can be related mainly to the atomic rough regions where the emission predominates. The small increase in the work function $\phi$ in the low exposure range (Figs. 4-7b) can be explained by the formation of a negatively polarized adspecies $\beta^{-}$(dipoles with the negative pole pointing away from the surface) adsorbed on the $V$ layers. The decrease of $\phi$ at the higher exposure can be understood as a result of creation of positively polarized hydrogen adspecies $\beta^{+}$. The latter should be incorporated below the surface and their nature is similar to that observed for hydrogen in bulk of vanadium. It is well known that vanadium crystals can dissolve large quantities of hydrogen on interstitial sites $[1,6,7]$. Our experimental techniques do not allow to estimate both the concentration of the $\beta^{+}$species in the bulk vanadium layer and $\beta^{-}$on its surface. After each high exposure to hydrogen, evacuation of the field emission tube caused undoubtedly partial desorption of the $\beta^{+}$adspecies and such high concentration of the adspecies on the surfaces as in the experiments presented in Refs. [13-19] was probably not obtained. The irregular changes and the relatively extensive scatter of $\Delta \phi$ in the saturation of the curves in Figs. $6 \mathrm{~b}-7 \mathrm{~b}$ can reflect the reaction of hydrogen with vanadium layers. The accompanying phenomenona were observed: surface reconstruction occurs [22] and even morphology of the layers changes. In consequence, the scatter of $\Delta \phi$ appears. The resolution of $\mathrm{FE}$ microscopy is not sufficiently high to observe such changes. The scatters of $\Delta \phi$ are accompanied by similar behavior of the preexponential term of the $\mathrm{F}-\mathrm{N}$ equation given in these figures. The reason for this is apparently connected with the fact that hydrogen reaction causes changes in the effective microscopic emitting area of a given region which is represented in the preexponential term [23]. The effect of structural rearrangement is more pronounced for the adsorption of hydrogen at $78 \mathrm{~K}$.

\subsection{Field emission patterns}

Figure 8 shows: (a) FE micrographs of the clean W emitter, (b) after exposure to hydrogen, (c) the clean emitter with a preadsorbed vanadium layer $\Theta_{\mathrm{V}}=10$, (d) after final exposure to hydrogen at room temperature. The result of a computer subtraction of the images presented in Figs. 8c and $8 \mathrm{~d}$ is shown in Fig. 9. (The subtracted images were taken at the same field strength.) The greatest emission increase upon exposure was observed around the $\{001\}$ planes particularly in the zones $\{001\}-\{011\}$ while the decrease in the emission - in the $\{111\}$ regions. This is also confirmed by the estimation of the work function from the F-N computer characteristics. Adsorption of hydrogen at $78 \mathrm{~K}$ resulted in the greatest increases in the work function of $\{111\}$ planes and their surroundings with preadsorbed vanadium. It seems that on this atomically rough substrate a pseudomorphism occurs in the first monolayer, and an open structure of the surface results in multiple adsorption (the radius of $\mathrm{V}$ and $\mathrm{W}$ atoms is similar). On such rough regions the adsorption of hydrogen can occur, similarly to the adsorption on the thin films (e.g. titanium [17]). The first doses of hydrogen cause formation of the $\beta^{-}$adspecies stable on the surface. With the increasing exposure the $\beta^{+}$adspecies can be also formed. They are not stable on the surface and can be incorporated quickly below the surface due to the concentration gradient [17]. 


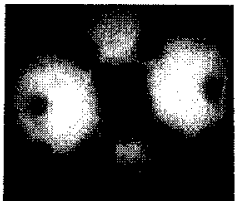

a)

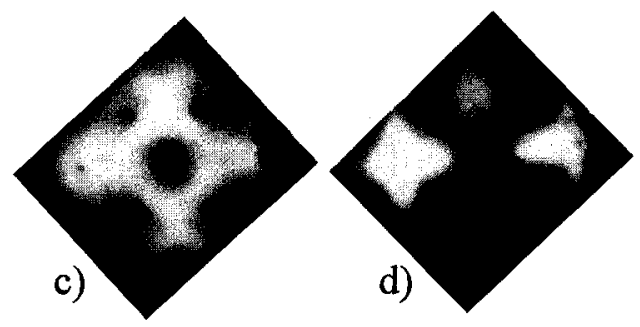

Fig. 8. FE micrographs: (a) of the clean $W$ emitter, (b) after exposure to hydrogen, (c) the clean emitter with a preadsorbed vanadium layer $\Theta_{\mathrm{V}}=10$, (d) after final exposure to hydrogen.

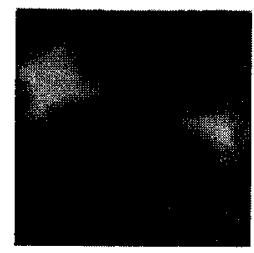

Fig. 9. Results of a computer subtraction of the emission. patterns represented in Figs. $8 \mathrm{c}$ and $8 \mathrm{~d}$.

According to [17], after partial saturation of the bulk with hydrogen (at a higher pressure) the $\beta^{+}$adspecies can also stay on the surface causing the increase in the $\triangle S P$ [17]. However, evacuation of the tube results in the desorption of some $\beta^{+}$adspecies [17]. The increase in work function of vanadium coated (111) region after exposure to hydrogen indicates that under UHV conditions mainly the $\beta^{-}$adspecies are adsorbed (stable) on such surface. We suppose that reaction of hydrogen with vanadium layer is very effective on atomically "open" surface and leads to the creation of vanadium hydrides. According to [12] dissociation of $\mathrm{H}_{2}$ preferentially occurs on such regions of tungsten.

Around the $\{100\}$ planes which consist nearly of close packed steps and edges, adsorption of $\mathrm{V}$ atoms beyond a monolayer coverage can lead to expansion of some steps (terraces) in the vicinity of similar nanostructures on the substrate surface. This is a smooth process as far as coverage is concerned. The problem of pseudomorphism in ultrathin layer is considered e.g. in [24]. On such modified substrate, consisting of the vanadium steps and edges, the adsorption of hydrogen results in a small reduction of the work function at higher hydrogen coverages. This indicates the electropositive character of the hydrogen adsorption, i.e., some 
amount of $\beta^{+}$species can stay around the $\{001\}$ regions under UHV conditions. For comparison, hydrogen adsorbed on close packed W(110) plane causes a decrease in work function $(0.49 \mathrm{eV})$ [12] whereas on $\mathrm{Nb}(110)$ and $\mathrm{Nb}(100)$ its increase $(0.1 \mathrm{eV}$ and $0.55 \mathrm{eV}$, respectively) $[25,26]$.

\subsection{Hydrogen solubility}

At room temperature the exposure corresponding to the saturation of the $\Delta \phi(\mathrm{H})$ curves increases with increase in vanadium coverage $\Theta_{\mathrm{V}}$. Figure 10 shows that increase in vanadium coverage $\Theta_{\mathrm{V}}$ is almost linear function of the exposure. It is not certain what value of the exposure corresponds exactly to the saturation of the $\Delta \phi$ and the plot is based only on 5 experimental points. However, a linear character of $\Theta_{V}$ dependence on exposure is preserved as it can be seen in Fig. 10. The coverage effect cannot be a result of hydrogen sticking probability decrease

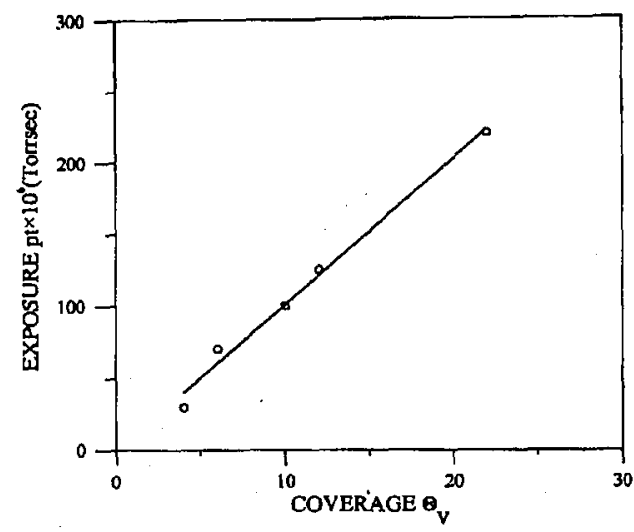

Fig. 10. Plot of hydrogen exposure versus vanadium coverage $\Theta_{\mathrm{V}}$ for the $\Delta \phi$ in saturation (at room temperature).

with increasing vanadium coverage, because the surface properties of vanadium adlayer should be coverage independent at $\Theta_{\mathrm{V}} \geq 4$. We believe that hydrogen solubility in vanadium is responsible for the coverage effect. According to [1] the solubility of hydrogen in the vanadium crystal decreases sharply with decreasing temperature, e.g. from $2 \%$ at room temperature to $0.3 \%$ at $220 \mathrm{~K}$ [1]. According to Refs. [1, 8] hydrogen absorption leads to vanadium adlayers expansion. The structural changes in the adlayers could also take place. Small but distinct minima of the $\Delta \phi$ in the saturation part of the curves (Figs. $6 \mathrm{~b}$ and $7 \mathrm{~b}$ ) are observed. They could reflect the structural changes.

\subsection{Thermal desorption of hydrogen from vanadium layer}

The studies of hydrogen thermal desorption from vanadium adlayers of $\Theta_{\mathrm{V}}=40$ were carried out. The experimental procedure and calculations were similar to those applied by Gomer et al. [10] for desorption of hydrogen from tungsten. Although the method used does not allow to determine the order of kinetic 
equation, the information on the temperature range of desorption and the activation energy of desorption can be obtained. This can be achieved measuring

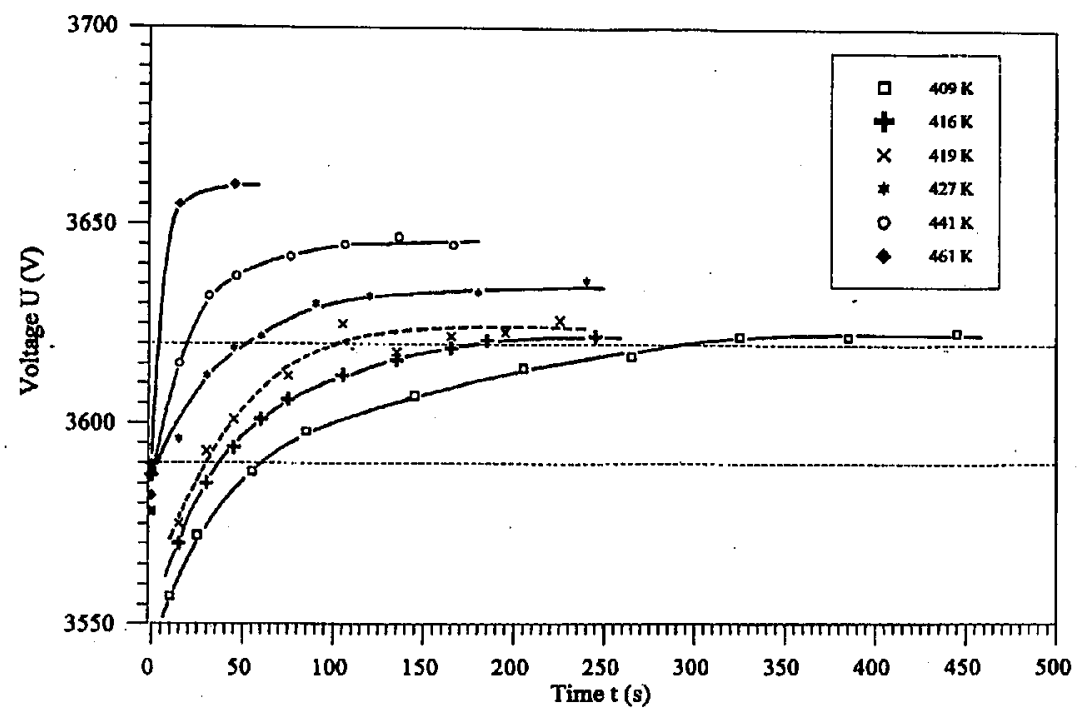

Fig. 11. High voltage required to draw a given emission current during thermal desorption of hydrogen. Horizontal dashed lines show the initial and end stage of desorption for which the desorption times were determined.

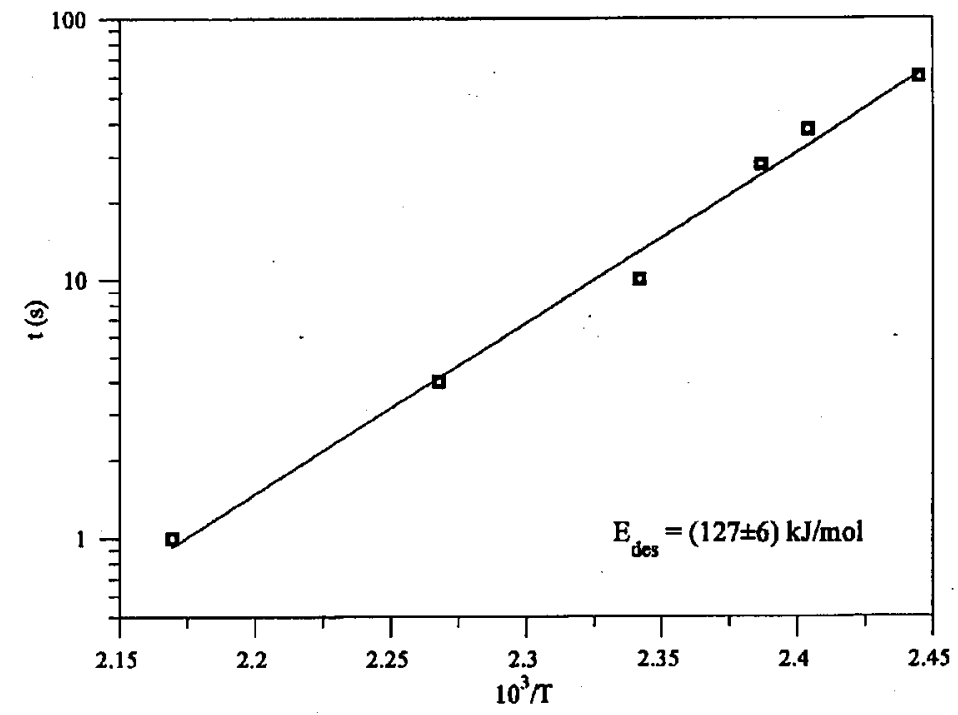

Fig. 12. Arrhenius plot of the desorption times for very low coverage of hydrogen. 
the time of desorption which is required to remove hydrogen adsorbate present at very low coverages range at various temperatures. The changes of hydrogen coverage were determined by measuring the high voltage at a given emission current and taking the field emission patterns. Such dependences are presented in Fig. 11. Horizontal lines in the figure show the initial and the end stage of the desorption for which the desorption time was determined. Arrhenius plot of the desorption time is presented in Fig. 12. Hydrogen was desorbed within the temperature range 409-461 K with an activation energy for desorption $127 \pm 6 \mathrm{~kJ} / \mathrm{mol}$.

As was noted in Sec. 3.3 the thermal desorption should be limited by diffusion of hydrogen from the bulk to the surfaces. However, from the studies of adsorption of hydrogen e.g. on $\mathrm{Nb}$ [15] and $\mathrm{Ti}$ [17-19] thin films one can conclude that within low coverage range hydrogen is adsorbed on the surface in the form of $\beta^{-}$species. The penetration to the volume is expected for higher coverages after all $\beta^{-}$states have been occupied. As it is suggested in Ref. [27] the thermal desorption of hydrogen from $\mathrm{Nb}$ wire is bulk diffusion limited for coverages higher than a monolayer.

\section{Conclusions}

1. Adsorption of vanadium on the tungsten field emitter lowered the total work function by about $0.48 \mathrm{eV}$ (in the saturation).

2. In contradistinction to the clean emitter of tungsten, the interaction of hydrogen with vanadium layers preadsorbed on the tungsten caused at first a small increase and then a reduction of the total work function (by $\approx 0.1 \mathrm{eV}$ ) at higher hydrogen exposure. The increase is attributed mainly to the hydrogen reaction on the atomically rough region of the vanadium layers, namely around $\{111\}$ planes whereas the reduction to the surrounding of the $\{100\}$ planes.

3 . In the range of very low coverage hydrogen was desorbed from the multilayer of vanadium on tungsten $\left(\Theta_{\mathrm{V}}=40\right)$ in the temperature interval $409-461 \mathrm{~K}$ with the activation energy of $127 \pm 6 \mathrm{~kJ} / \mathrm{mol}$.

\section{Acknowledgment}

We gratefully acknowledge Professor Ryszard Duśs suggestion of this research, his continuous interest and stimulating discussions. Thanks are also due to Professor Ryszard Męclewski for many discussions and his help during the course of the study. We would also like to thank Stanisław Surma for helpful remarks on the manuscript.

The work was supported by the Committee for Scientific Research, grant number 2 P303 $12006 \mathrm{p} 02$.

\section{References}

[1] T. Schober, H. Wenzel, in: Hydrogen in Metals, Eds. G. Alefeld, J. Völkl, Vol. 29 of Topics in Applied Physics, Springer, Berlin 1978, p. 12.

[2] Proc. First Int. Symp. Hydrogen in Metals and Metal Hydrides, Stuttgart 1988, Eds. R. Kirchheim, E. Fromm, E. Wicke, Oldenburg, München 1988.

[3] Proc. Third Int. Symp. Hydrogen in Metals and Metal Hydrides, Uppsala 1992, Eds. D. Noreus, S. Rundqvist, L. Wicke, Oldenburg, München 1992. 
[4] H. Sugimoto, J. Phys. Soc. Jpn. 53, 2592 (1984).

[5] T. Suzuki, H. Namazue, S. Koike, H. Hayakava, Phys. Rev. Lett. 51, 798 (1983).

[6] F. Stillesjö, S. Ólafsson, P. Isberg, B. Hjörvarsson, J. Phys. Condens. Matter 7, 8139 (1996).

[7] B. Hjörvarsson, J. Rydén, E. Karlsson, J. Birch, J.E. Sundgren, Phys. Rev. B 43, 6440 (1991).

[8] B. Hjörvarsson, S. Ólafsson, F. Stillesjö, E. Karlsson, J. Birch, J.E. Sunder, Z. Phys. Chem. Bd 1881, 343 (1993).

[9] E.W. Müller, T.T. Tsong, Field Ion Microscopy, Harvard University Press, Cambridge, MA 1963.

[10] R. Gomer, R. Wortman, R. Ludny, J. Chem. Phys. 26, 1147 (1957).

[11] E. Chrzanowski, Acta Phys. Pol. A 44, 711 (1973).

[12] R.S. Polizzotti, G. Ehrlich, J. Chem. Phys. 71, 1 (1979).

[13] R. Duś, E. Nowicka, Z. Wolfram, Surf. Sci. 216, 1 (1989).

[14] E. Nowicka, R. Duś, Prog. Surf. Sci. 48, 3 (1995).

[15] R. Duś, Surf. Sci. 52, 440 (1975).

[16] E. Nowicka, R. Duś, Surf. Sci. 185, 587 (1987).

[17] R. Duś, E. Nowicka, Z. Wolfram, Surf. Sci. 269, 545 (1992).

[18] E. Nowicka, R. Duś, Langmuir 12, 1520 (1996).

[19] E. Nowicka, Vacuum 47, 193 (1996).

[20] E. Nowicka, Z. Wolfram, R. Duś, Acta Phys. Pol. A 81, 117 (1992).

[21] T.B. Grimley, in: Chemisorption, Ed. W.E. Garner, Butterworths, London 1957, p. 17.

[22] K. Christmann, Prog. Surf. Sci. 48, 15 (1995).

[23] R. Gomer, Field Emission and Field Ionization, Harvard University, Cambridge, MA 1961.

[24] M.F.H. van Tol, F.A. Hondsmerk, J.W. Bakker, B.E. Nieuwenhuys, Surf. Sci. 206, 214 (1992).

[25] T.W. Haas, J. Appl. Phys. 39, 5854 (1968).

[26] D.T. Hagen, F.E. Donalden, Surf. Sci. 45, 61 (1974).

[27] S.M. Ko, L.D. Schmidt, Surf. Sci. 42, 508 (1974). 